\title{
Xanthogranulomatous endometritis- a rare pathological entity presenting as infertility
}

\author{
Rani E. ${ }^{1}$, Suri V. ${ }^{2}$, Sandhu J. ${ }^{3}$, Goel N. ${ }^{4}$, Kaur P. ${ }^{5}$, \\ ${ }^{1}$ Dr. Ekta Rani, Assistant Professor, ${ }^{2}$ Dr. Vijay Suri, Professor, ${ }^{3}$ Dr. Jasmine Sandhu, Senior Resident, ${ }^{4}$ Dr. Nikita Goel, Junior \\ Resident, ${ }^{5}$ Dr. Prabhjot Kaur, Junior Resident, All authors are affiliated with the Department of Pathology, Adesh Institute Of \\ Medical Sciences and Research, Bathinda, Punjab, India.
}

Corresponding Author: Dr. Ekta Rani, Assistant Professor, Department of Pathology, Adesh Institute of Medical Sciences and Research, Bathinda, Punjab, India. Email: eku.2001@gmail.com

\begin{abstract}
Xanthogranulomatous inflammation is a distinguished histopathological entity affecting several organs, most likely kidney and gall bladder. Only a small number of cases of xanthogranulomatous endometritis (XGE) are reported in literature so far. Microscopic examination show sheets of foamy histiocytes along with other inflammatory cells on H\&E stains sections. We present a case of 31-year-old female with complaint of inability to conceive for 3 years and having history of previous 3 tubal pregnancies. Hysteroscopy examination reveals fluffy endometrium, patent bilateral fornices with normal cervical mucosa. Dilatation and curettage were done and sent for histopathological examination, and diagnosis of Xanthogranulomatous Endometritis was made. As XGE is a rare inflammatory disease, awareness of this lesion is necessary for both the gynaecologist and pathologist and should be kept in differential diagnosis in the cases of infertility.
\end{abstract}

Keywords: Xanthogranulomatous endometritis, Endometrium, Young, Infertility

\section{Introduction}

Xanthogranulomatous endometritis (XGE) is an unusual pathological entity characterized by foamy histiocytes, other inflammatory cells comprising of lymphocytes, plasma cells and foreign body type of giant cells. It affects several organs most commonly involving gall bladder and kidney. Bone, urinary bladder, testis, vagina, fallopian tubes and endometrium can also be affected rarely [1]. Xanthogranulomatous endometritis had synonyms as histiocytic endometritis, pseudoxanthomatous endometritis. The average age affected is 72 years. Most common symptoms are irregular coporrhagia, discharge, cervical stenosis and pyometra. Xanthogranulomatous endometritis is divided into two groups: one is pure XGE and other is XGE associated with endometrial carcinoma.
Xanthogranulomatous inflammation of female genital tract is an inflammatory disease with unclear etiological factors and pathogenicity. There are multiple theories related to pathogenesis. First is theory of infection which is supported by bacterial culture of E-coli, Salmonella etc. Other theories are associated with intrauterine devices, endometriosis and lipid metabolism of macrophages and drugs. Prognosis of Xanthogranulomatous endometritis is variable. Some cases recovered after antibiotic therapy and some were nonresponsive $[2,3,4]$.

We found only few cases of Xanthogranulomatous endometritis reported in Indian Literature. But a case is yet be reported with infertility as presenting symptom.

\section{Case Report}

We present a case of 31-year-old young female who presented with a complaint of inability to conceive for 3 years with 3 previous tubal pregnancies. There is history of bilateral salpingectomy because of tubal pregnancies. Hysteroscopy findings shows clear bilateral fornices and healthy cervix and vagina. Menstrual history is normal. Laboratory investigations are within normal limits. Grossly, we received multiple grey brown to hemorrhagic soft tissue bits altogether measuring $0.4 \times 0.3 \times 0.1 \mathrm{~cm}$. Hematoxylin and eosin (H\&E) stained sections showed sheets of foamy macrophages, few of them showing eosinophilic cytoplasm along with lymphocytes and few neutrophils. Few fragmented endometrial glands and occasional interspersed blood vessels also seen. No evidence of hyperplasia/malignancy was noted. Serological markers for endometrial carcinoma and special stains for AFB and fungus were also negative. The diagnosis of Xanthogranulomatous Endometritis was made.

Manuscript received: $28^{\text {th }}$ November 2019

Reviewed: $5^{\text {th }}$ December 2019

Author Corrected: $14^{\text {th }}$ December 2019 Accepted for Publication: $17^{\text {th }}$ December 2019

Pathology Update: Tropical Journal of Pathology \& Microbiology Available online at: www.medresearch.in 1050 | P a g e 


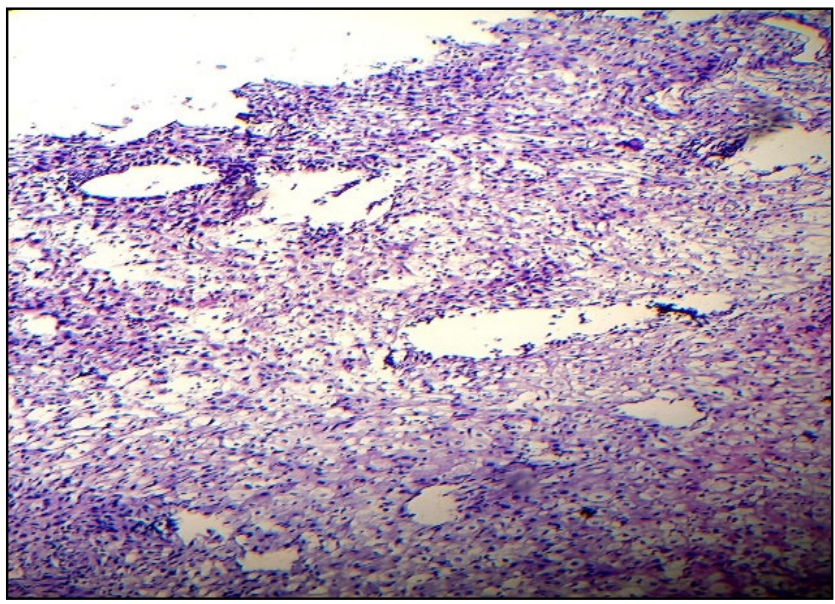

Fig-1: Photomicrograph showing numerous foamy histiocytes along with few fragmented endometrial glands showing infiltration of lymphocytes and plasma cells (10x- H\&E).

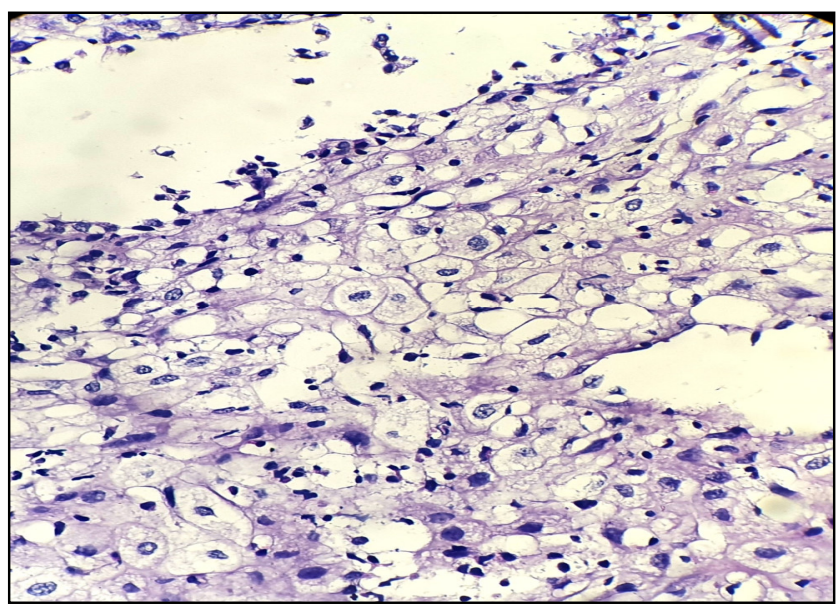

Fig-2: Photomicrograph showing many foamy histiocytes admixed with lymphocytes (40x- H \&E).

\section{Discussion}

Xanthogranulomatous Endometritis or Histiocytic Endometritis is a rare entity comprising, collections of foamy macrophages. Barua et al [5]. described the first case of XGE without evidence of endometrial carcinoma or hyperplasia. The age at onset ranges from 59-88 years, with an average age of 72 years. The complaints are menorrhagia, excessive leucorrhea, cervical stenosis or pyometra. There are two groups of xanthogranulomatous endometritis - one is pure Xanthogranulomatous endometritis and other is xanthogranulomatous endometritis associated with endometrial carcinoma [3].

The etiologic factor, pathogenesis of XGE is not clear yet. Many theories have been proposed

1) Theory of infection

2) Endometriosis

3) IUCDs

4) Inborn lipid metabolism of macrophages and drugs [6].

5) The development of XGE may also be influenced by Radiation therapy or necrosis, excessive intra-uterine hemorrhage and cervical stenosis [7].

We report a case of 31 years old female. Age is in concordance to the 2 cases of study of Zang et al [6] showing 32 years and 21 years while 1 case is of age 62 years. But the studies of Ekici et al [8] and Makkar et al [9] were showing discordance with our case, having 67 years and 45 years old females respectively. 
Chief complaint of our case was inability to conceive with history of previous abortions. There is no such case reported till date having these symptoms. In the study of Ekici et al [8] patient had complaint of Post- menopausal bleeding while the female in study of Makkar et al [9] presented with continuous bleeding per vaginum for last 3 months with irregular menstrual history for 1 year. The case series of Zang et al [6] showed varying complaints - Pain lower abdomen, Irregular bleeding, fever, abdominal discomfort and discharge per vaginum.

Upto now, only a small number of cases of xanthogranulomatous inflammation of female genital tract have been reported, endometrium is most frequently affected and may be associated with endometrial carcinoma $[7,10,11]$.

Table-1: Number of cases showing Pure XGE and association with endometrial carcinoma.

\begin{tabular}{|c|c|c|c|c|c|c|c|}
\hline & $\begin{array}{c}\text { Present } \\
\text { case }\end{array}$ & $\begin{array}{c}\text { Barua et } \\
\text { al [5] }\end{array}$ & $\begin{array}{c}\text { Blanco } \\
\text { et al [12] }\end{array}$ & $\begin{array}{c}\text { Russack and } \\
\text { Lammers } \\
{[11]}\end{array}$ & $\begin{array}{c}\text { Buckley and } \\
\text { Fox [13] }\end{array}$ & $\begin{array}{c}\text { Pounder and } \\
\text { Iyer [7] }\end{array}$ & $\begin{array}{c}\text { Ashkenazy } \\
\text { et al [10] }\end{array}$ \\
\hline XGE & 1 case & 1 case & 1 case & & 2 cases & & 2 cases \\
\hline $\begin{array}{c}\text { XGE associated } \\
\text { with endometrial } \\
\text { carcinoma }\end{array}$ & & & & 6 cases & & 1 case & 2 cases \\
\hline
\end{tabular}

Table 1 shows that there is frequent association of Xanthogranulomatous endometritis with Endometrial carcinoma. Our case is a pure Xanthogranulomatous endometritis which is similar to the findings of Barua et al [5], Blanco et al [12] \& Buckley and Fox [13]. In 1990, Russack and Lammers [11] reported six XGE cases associated with endometrial carcinoma. The pathogenesis of their cases was supposed to be associated with radiation therapy for endometrial carcinoma. Pounder and Iyer [7] reported a case of XGE associated with endometrial adenocarcinoma. The foamy macrophages contained brown pigment that supposed to be lipofuscin or hemosiderin. Ashkenazy et al. described four cases with endometrial foamy cells. Two cases were presented with endometrial hyperplasia or carcinoma and other two were Pure XGE.

The irregular and necrotic appearance of XGE may mimic carcinoma grossly, as also reported by Ekici et al in 2007 [8].

The presence of foamy histiocytes infiltrating the myometrium might be misdiagnosed as Clear cell carcinoma or Sarcoma, although immunohistochemical stains can resolve the issue.[9]

\section{Conclusion}

1)Xanthogranulomatous Endometritis is very rare pathological entity.

2)It should be kept in differential diagnosis of infertility cases in young females.

3)The presence of XGE does not exclude the possibility of accompanying carcinoma. Due to this, sampling of the entire endometrium should be considered in these patients and regular follow up should be advised.

Funding: No funding sources

Conflict of interest: None declared

Ethical Approval: Not required

\section{References}

1. Rosai J. Rosai and Ackerman's Surgical Pathology. In: Rosai J, $9^{\text {th }}$ ed. Missouri: Mobsy; 1996. pp.1042-3.

2. Shalev E, Zuckerman H, Rizescu I. Pelvic inflammatory pseudotumor (Xanthogranuloma). Acta Obstet Gynecol Scand, 1982;61(3):285-286. doi: https://doi.org/10. 3109/ 00016348209156575.
3. Pace EH, Voet RL, Melancon JT. Xanthogranulomatous oophoritis: an inflammatory pseudotumor of the ovary. Int J gynecol Pathol,1984;3(4):398-402.

4. Ladetoged C, Loretzen M. Xanthogranulomatous inflammation of the female genital tract. Histopathology, 1988; 13(5):541-551. doi: https://doi.org/10.1111/j.13652559. 1988.tb02078.x.

5. Barua R, Krikland JA, Petrucco OM. Xanthogranulomatous Endometritis: A case report. Pathol. 1978;10(2): $161-164$.

6. Zhang X, Dong H, Zhang LL, Desouki M, Zhao C. Xanthogranulomatous Inflammation of the Female Genital Tract: Report of Three Cases. J Cancer. 2012;3:100-106. doi: $10.7150 /$ jca.3929.

7.Pounder DJ, Iyer PV. Xanthogranulomatous Endometritis associated with endometrial carcinoma. Arch Pathol Lab Med. 1985;109(1):73-75. 
8. Ekici ID, Usubutum A, Kucukali T. Xanthogranulomatous Endometritis: A challenging imitator of endometrial carcinoma. Infect Dis Obstet Gynecol. 2007:34763. doi: http://dx.doi.org/10.1155/2007/34763.

9. Makkar M, Gill Mk, Singh DP. Xanthogranulomatous Endometritis: An Unusual Pathological Entity Mimicking Endometrial Carcinoma. Ann Med Health Sci Res. 2013;3 (1) : 48-49. doi: 10.4103/2141-9248.121222.

10. Ashkenazy M, Lancet M, Borenstein R, Czernobilsky B. Endometrial foam cells. Non-estrogenic and estrogenic. Acta Obstetrica et Gynecologia Scandinavica. 1983;62(3): 193-197.doi:https://doi.org/10.3109/0001634830915 5791.
11. Russack V, Lammers RJ. Xanthogranulomatous endometritis. Report of six cases and a proposed mechanism of development. APLM. 1990;114(9):929932.

12. Blanco C, Fernandez F, Buelta, Garijo F, Val- Bernal JF, Sanchez S. Xanthomatous endometritis. App Pathol. 1989; 7(4):273-276.

13. Buckley $\mathrm{CH}$, Fox H. Histiocytic endometritis. Histopathol. 1980; 4(1):105-110. doi: https://doi.org/ 10. 1111/j. 1365-2559.1980.tb02902.x.

\section{How to cite this article?}

Rani E, Suri V, Sandhu J, Goel N, Kaur P. Xanthogranulomatous endometritis- a rare pathological entity presenting as infertility. Trop J Path Micro 2019;5(12):1050-1053.doi:10.17511/jopm.2019.i12.14 